\title{
DENTRO DAS BRUMAS DO TEMPO. CONSIDERAÇÕES PRELIMINARES ACERCA DO ANTES, DO DURANTE E DO PÓS PANDEMIA NAS ARTES E NA SOCIEDADE
}

WITHIN TIME MISTS. PRELIMINARY CONSIDERATIONS ABOUT THE BEFORE, THE DURING AND THE POST PANDEMIC TIMES IN ARTS AND SOCIETY

DANS LES BRUMES DU TEMPS. CONSIDÉRATIONS PRÉLIMINAIRES SUR L'AVANT, LE PENDANT ET L'APRÈS LA PANDÉMIE DANS LES ARTS ET LA SOCIÉTÉ

DENTRO DE LAS BRUMAS DEL TIEMPO. CONSIDERACIONES PRELIMINARES SOBRE ANTES, DURANTE Y POST PANDEMIA EN LAS ARTES Y LA SOCIEDAD

\section{Paula Guerra}

Universidade do Porto, Faculdade de Letras e Instituto de Sociologia, CITCEM, CEGOT, Dinâmia'CET, Griffith Centre for Cultural Research, Porto, Portugal

\section{Lígia Dabul}

Universidade Federal Fluminense, Programa de Pós-Graduação em Estudos Contemporâneos das Artes da e do Programa de Pós-Graduação em Sociologia, Rio de Janeiro, Brasil

Por entre as brumas e a atualidade de uma memória. É assim que vivemos há mais de um ano. Por um lado, temos a sombra daquela que era a nossa "normalidade": a neblina de uma série de condições, de vivências e de existências que tomávamos como garantidas e que, repentinamente, desapareceram. Por outro lado, temos uma atualidade que parece passar sem se vincular a nós, quase como se de uma névoa se tratasse. Vivemos numa quase dicotomia de uma atualidadepassado que decorre sem nos darmos conta porque não a vivemos na totalidade. A primeira leitura dos artigos que integram este Volume derradeiro de 2020 leva-nos a este sentir. Todos os artigos - interessantemente - cruzam o presente e o passado, bem como uma condição de outsider de vislumbre face a ambos. A pandemia da COVID-19 talvez seja a principal responsável por esta consequência impremeditada na tradição mertoniana. Em primeiro lugar, pelo facto de ter provocado um confinamento prolongado, tornando quase impossível a vivência da "antiga normalidade". Além disso, esta crise sanitária mundial trouxe consigo um conjunto de imprevisibilidades em todos os níveis e referentes a todos os setores que compõem, e que contribuem para o funcionamento das sociedades. Os setores artístico-cultural e criativo foram os primeiros a serem matizados por essa imprevisibilidade, mas ainda pela dureza e a resistência deste vírus.

Além disso, parece que a ausência da arte sob a forma física contribuiu largamente para a existência de uma atualidade/vivência não vinculada. Mais, esta atualidade mais parece um jogo de multiple players, encontrando-se envolta em questões, dúvidas, incertezas, medos e debates na maioria das vezes titubeantes - e que acontecem num tempo célere (Guerra \& Alberto, 2021). Como alguns autores enunciam, estamos perante um contexto de crise duradoura (Santos, 2020). Pensando na memória social de Bourdieu (2004), com o engajamento nas redes sociais e nas mais diversas plataformas sociais, com o intuito de promover a sobrevivência das expressões artísticoculturais - e dos artistas e agentes responsáveis -, podemos, em certa medida, vislumbrar pequenos suspiros de vida e lufadas de ar que nos apontam para um caminho promissor. Mas 
pessimismo e otimismo andam, aqui, nas artes e na cultura, de mãos dadas. Apesar de se tratar de um futuro incerto, o presente no qual nos encontramos é ainda mais incerto (Frances et al., 2021). E a realidade é dura. Os trabalhadores das artes e cultura foram confrontados com um rápido colapso de empregos devido ao encerramento de locais de trabalho e regras de distanciamento social, isto depois de um longo período de diminuição de salários, aumento da precariedade, elevado endividamento. A crise atual descobriu uma grave falta de capacidade de resposta dos Estados à endémica crise do setor cultural e artístico (Banks \& O'Connor, 2020).

Por mais importante que seja abordar as necessidades económicas imediatas dos trabalhadores culturais, empresas e organizações, o foco também precisa de ser alargado. Em parte, isto significa olhar para a forma como o setor cultural se manteve em crise, o que o tornou tão vulnerável para além dos impactos particulares do vírus. Após 2008, o setor cultural foi considerado "resiliente". No entanto, a resiliência foi muitas vezes confundida com sobrevivência. E, embora o apoio à comunidade artística tenha sido utilizado para assinalar um compromisso com o cosmopolitismo, a diversidade e a multicultura, também tem sido igualmente utilizado para reforçar a primazia dos símbolos e instituições nacionais que têm tendido a negar a possibilidade da variedade inclusiva. Nestas circunstâncias, encontrar uma nova voz para a cultura pode também funcionar como um estímulo para a reinvenção, ou a redescoberta do social, como uma relação partilhada de apoio à vida comum, em vez de uma infraestrutura decadente. Como em outros períodos de grande turbulência social, foi a arte e a cultura que proporcionaram um sítio chave no qual estas transformações puderam ser registadas, digeridas: têm sido o local onde uma resposta pode ser encontrada.

A COVID-19 tem apresentado muitos desafios à indústria cultural e aos artistas que dependem da performance ao vivo não só como fonte de receitas, mas também como parte integrante da sua estratégia de lançamento e de envolvimento do seu público. É importante avaliar as modalidades de expressão artística quando confrontadas com um novo paradigma do "socialmente distante". Não obstante muitas das plataformas utilizadas por artistas independentes estejam em funcionamento há anos, a pandemia está a promover mais inovação disruptiva, de uma perspetiva tecnológica, para satisfazer a procura dos consumidores e enquanto um método de expressão mais profundo e envolvente, cultivado pelos artistas quando trabalham remotamente com o seu público. Isto significa que, em vez de envolver uma transição sem falhas do físico para o virtual, será necessário um período de ajustamento, uma vez que a tecnologia alcança efetivamente as novas exigências impostas pela pandemia da COVID-19 (Frenneaux \& Bennett, 2021). Quando tomamos emprestado o conceito de "polifonia" do campo da música para o da cultura, tal significa uma pluralidade de ideias, de expressões e de linguagens que constituem o quotidiano das pequenas produções culturais podem ser visibilizadas e expressadas mais facilmente pelas e nas cenas virtuais. Então, nem tudo está perdido.

A relação entre a bruma, a atualidade e o futuro surgem no seguimento de uma ideia de Paul Crutzen - que foi galardoado com o Prémio Nobel de Química, em 1995 - espelhada no início do século XXI - muito longe de falar de uma pandemia - e que diz respeito à ideia de Antropoceno. Este conceito ou ideia - como lhe quisermos chamar - relaciona-se intimamente com as noções e as tentativas de entendimento das mudanças históricas. Crutzen enuncia mesmo que o Antropoceno diz respeito ao que é historicamente recente e, ainda que as suas conclusões sejam direcionadas para o campo científico da geologia e da ecologia, as mesmas assumem-se tanto mais 
premente quando nos movemos para as ciências sociais, como a sociologia, a antropologia ou a história (Steffen, Crutzen \& McNeill, 2007). Aliás, serão estas também fundamentais para, no futuro, compreender aquela que foi a pandemia da COVID-19, ou pelo menos para perceber aquilo que nós, agora, não somos capazes. A principal ideia é que a humanidade e a cultura têm um papel central.

Porventura, outros autores como Bruno Latour (2014) afirmam que a nova era apelidada de Antropoceno se refere a uma rápida e eficaz rutura com o mundo, e com a vida que fora anteriormente experimentada. As transformações provocadas pela pandemia a múltiplos descompassos entre a sustentabilidade, as lógicas de enfrentamento da realidade e as crises económicas, sociais, políticas e culturais. Então, no contexto do Antropoceno (Akinruli \& Akinruli, 2020), a memória assume um papel de destaque, mas também a cultura no sentido em que ambas nos direcionam para outros contextos que não os de catástrofe constante. Estamos, assim, perante novos regimes de historicidade que devem ser estudados e protegidos, pois refletem ainda processos próprios de dicotomização entre o Sul e o Norte Globais, bem como entre o Ocidente e o Oriente Mundial, algo que vai ao encontro do que Hartog (2006) enuncia face à Queda do Muro de Berlim, pois esse evento marcou um breaking point na história da humanidade. Estamos, portanto, num limbo outra vez. Entre a amnésia e a vontade de esquecer. Entre a memória do passado e a vivência de um presente não promissor. As nossas significações, identificações e quotidianos de hoje, serão o que fomentará o conhecimento do amanhã, bem como irão demarcar uma nova - ainda que distante - contemporaneidade. A memória, as artes e a cultura nunca foram tão preponderante para o social como o são atualmente, pois são os signos das identidades perdidas por entre processos fluídos de condicionalismos. Partindo da premissa dos novos regimes de historicidade, torna-se pertinente mencionar que também as instituições políticas possuem um papel charneira na ligação entre estes dois campos. São as agências políticas que ditam, em certa medida, quais as futuras historicidades, os avanços e os recuos dos países e dos seus modos de (des)envolvimento com o novo Antropoceno, nos moldes como anteriormente o caracterizamos.

Nesta encruzilhada, surge-nos o artigo Contributions to the debate on the agendas of the social economy in the culture in Turkey de Cihan Ertan. Neste texto, o autor procura retratar dos modos em que a globalização do setor económico, e as mudanças dos mecanismos do mercado trouxeram consigo diversos problemas, quer a nível individual como coletivo. Numa nova forma de condição pós-moderna de existência, Cihan relata as novas práticas económicas, tais como o empreendedorismo, o associativismo e a constituição de coletivos, enquanto formas de indicar meios alternativos de (sobre)vivência e resistência das identidades e culturas na Turquia. Na lógica dos regimes de historicidade, a investigadora premiada Ludivine Thouverez apresenta-nos o artigo Mémoire graphique et conflit: la violence de l'ETA dans la neuvième art. Através da análise de quatro obras artísticas de banda desenhada, Ludivine demonstra como os conflitos armados da ETA passaram de um conflito armado para um conflito de memória. Consequentemente, tem-se vindo a assistir a um alargamento conceptual da noção de património, através da afirmação de novas "agendas" patrimonialistas que evidenciam preocupações ligadas à salvaguarda, proteção e divulgação de "novos patrimónios" relacionados com espaços, paisagens, comunidades e formas de expressão cultural menos monumentais e mais imateriais e intangíveis/ilegítimos.

Situado ainda na memória e sua revivificação, deparamo-nos com o artigo de Eliska Altmann: Entre playas y distopías: el Río de Janeiro ex capital y la recepción cinematográfica. Sobre o Rio de 
Janeiro e sobre o cinema - talvez um dos principais meios de manter a ligação entre passado, presente e futuro -Eliska Altmann, com base em quatro filmes brasileiros, identifica um conjunto de imaginários sobre a cidade do Rio, ao mesmo tempo que estabelece uma socio-crítica, algo fundamental para percebermos o que fazer diferente no futuro. Assim, ao haver, inerente à memória e à arte, um processo profundo de aprendizagem, maneável e manipulável de acordo com os avanços e os recuos das sociedades, surgem espaços de experimentação urbana e societal. Salomé Uribe, com o artigo denominado Intervenção social pelas/através das artes: predisposições, desafios e propostas, parte de uma lacuna bibliográfica sobre indivíduos que intervém socialmente pelas ou através das artes, procurando cruzar áreas como a sociologia da cultura e das artes e tendo como inspiração as biografias singulares de artistas. Aliás, também a questão das biografias é central para compreendermos as realidades que nos rodeiam, no sentido que as mesmas denotam visões e perspetivas de vivências múltiplas, em diversos contextos e espaços.

Voltamos aos regimes de historicidade com Ana Paula Alves Ribeiro e com o seu artigo Rio de Janeiro e sua herança africana: histórias contadas por Zózimo Bulbul. Temos aqui novamente a memória, a cidade, o cinema. Ana Paula vem dar-nos conta de um passado-presente controverso no Brasil, nomeadamente com o trilho do cinema negro. Assim, Zózimo Bulbul, nas palavras da autora, assume um lugar preponderante no que diz respeito à manutenção de um registo mnemónico de uma cidade escondida. Além dos conflitos e da resistência, Ana Paula ainda nos guia pelos tempos, através dos olhos de Zózimo, mostrando-nos as manifestações culturais que fazem parte da identidade de um Rio de Janeiro negro, plural e multidimensional que tem sido sistematicamente obliterado pela cultura dominante. Andrea Copeliovitch apresenta-nos o texto designado Dançar o Zen: aprendizado e poéticas de um processo. Neste artigo, Andrea Copeliovitch debruça-se sobre processos experimentais e relacionais entre o Zen Budismo, Artraud, Grotowski e algumas danças brasileiras. A autora revê danças como bumba-meu-boi ou cavalo marinho à luz do corpo simbólico de Graziela Rodrigues, no sentido em que mapeia a intersecionalidade entre passado e presente, introduzindo dinâmicas contemporâneas das sociedades atuais, como o anime japonês.

Num excelente registo de pesquisa, Ana Alves da Silva apresenta-nos as Comunidades colaborativas, arte e design no Quarteirão Miguel Bombarda, Porto. Neste texto, a autora estabelece uma conceção entre o cruzamento das indústrias culturais e criativas e os projetos independentes. Tal como referimos anteriormente, novamente a importância de percebermos, registarmos e mapearmos as diferentes formas de vivência, produção e criação artística, dentro das sociedades, são elementos chave para conseguirmos, no futuro, perceber o nosso meio envolvente. A autora apresenta um marco teórico para um contexto mais alargado sobre a relevância social da arte e do design que ocupam o espaço público da rua - avançando com uma proposta de reflexão enquanto membro ativo da comunidade do Quarteirão Miguel Bombarda há mais de 15 anos.

Concomitantemente, Ondina Pires com o seu Ensaio sobre o campo artístico contemporâneo. Johnny Rotten vs John Lydon $=K O$, denota uma reflexão crítica sobre os condicionalismos políticos que pautaram/pautam o nosso presente, sendo aqui de importante realce a ligação entre o punk - enquanto sistema de resistência ao mainstream histórica e socialmente instituído - e a presidência de Donald Trump. Uma vez mais, vimos demonstrar a ligação, sempre turbulenta, 
entre o campo artístico e o campo político. Exemplo mais emblemático não podia existir: John Lydon. Através deste texto, e das ilustrações caricaturais a ele associadas, podemos observar uma trajetória decadente de um músico que é legitimado pelas "brechas" políticas e culturais da democracia, sistema este, sempre em perigo precisamente pela sua abertura a visões políticas diferentes e ao contínuo diálogo entre forças ideológicas, muitas vezes, opostas. Por fim, Gabriel Barth apresenta-nos duas recensões críticas: uma sobre o livro "Punk, Fanzines and DIY Cultures in the Global North"; e a outra sobre o livro "Redefining Art Worlds in the Late Modernity". No caso do primeiro livro, editado por Paula Guerra e Pedro Quintela, existe um foco analítico e empírico nas dimensões ocultas/ocultizadas do estudo das culturas, no sentido em que o livro se foca no entendimento das expressões DIY, nos movimentos punk e nas produções alternativas, nomeadamente nos fanzines. Assim, o fulcro deste livro são as histórias contemporâneas invisíveis. O segundo livro, editado por Paula Guerra e Pedro Costa, trata-se de um tributo a Howard S. Becker, ao longo do qual são abordados diferentes arts worlds de diversas partes do mundo. Partiu-se do passado para se reconfigurar o presente e quiçá o futuro.

Partiu-se do passado para se reconfigurar o presente e quiçá o futuro. É assim que a arte e a memória devem ser, uma série de (re)configurações sucessivas e social e temporalmente presentes e demarcadas. Ecoam, enfim, neste Volume, as palavras de Grada Kilomba quando observou que é "fundamental tornar o conhecimento vivo, corpóreo, físico". E mais: "através das artes consegues formular, sem impor, uma plataforma em que o público levanta questões que não estavam lá antes. Aí começa-se a descolonizar o conhecimento. Para mim, arte é isso: quando ela consegue entrar dentro de ti emocionalmente e fisicamente, e transformar-te." (Grada Kilomba In Duarte, 2017: s/p).

Porto e Rio de Janeiro, dezembro de 2020

\section{REFERÊNCIAS BIBLIOGRÁFICAS}

Akinruli, Luana Carla Martins Campos \& Akinruli, Samuel Ayobami (2020). Antropoceno, Arqueologia e memória social: A pandemia de COVID-19 como um evento crítico. Tessituras, Revista de Antropologia e Arqueologia, Programa de Pós-Graduação em Antropologia, 8 (1), 228-236.

Banks, Mark \& O'Connor, Justin (2020). "A plague upon your howling”: art and culture in the viral emergency, Cultural Trends, DOI: 10.1080/09548963.2020.1827931

Bourdieu, Pierre (2004). Os usos sociais da ciência. Por uma sociologia clínica do campo científico. São Paulo: UNESP.

Duarte, Mariana (2017). Grada Kilomba é a artista que Portugal precisa de ouvir. Ípsilon - Público. 18 de agosto de 2017. Disponível em https://www.publico.pt/2017/08/18/culturaipsilon/noticia/grada-kilomba-e-a-artistaque-portugal-precisa-de-ouvir-1782377

Frenneaux, Richard \& Bennett, Andy (2021). A new paradigm of engagement for the socially distanced artist. Rock Music Studies, DOI: 10.1080/19401159.2020.1852770

Guerra, Paula \& Alberto, Thiago Pereira (2021). Welcome to the 'modern age': The imagery of punk from the 1970s in the redefinition of the New York music scene of the 2000s and beyond. In Russ Bestley, Mike Dines, Paula Guerra \& Alastair Gordon (Eds.). Trans-Global Punk Scenes. The Punk Reader Volume 2. Bristol: Intellect Books.

Guerra, Paula (2020). Elogio da improbabilidade do património. In Gerciane Oliveira \& Kyara Vieira (Eds.). Patrimônio, povos do campo e memórias: diálogos com a cultura, a arte e a educação (47-66). Mossoró: EdUFERSA.

Hartog, François (2006). Tempo e património. Varia História, 22 (36), 261-273.

Howard, Frances, Bennett, Andy, Green, Ben, Guerra, Paula, Sousa, Sofia \& Sofija, Ernesta (2021). 'It's turned me from a professional to a 'bedroom DJ' once again': COVID-19 and new forms of inequality for young musicmakers'. YOUNG: Nordic Journal of Youth Research, DOI: 10.1177/1103308821998542.

Latour, Bruno (2014). Os Mil Nomes de Gaia: do Antropoceno à Idade da Terra. Rio de Janeiro, set. 2014. Disponível em: https://www.youtube.com/c/osmilnomesdegaia 
Santos, Boaventura de Sousa (2020). A cruel pedagogia do vírus. Coimbra: Almedina.

Steffen, Will, Crutzen, Paul \& McNeill, John (2007). The Anthropocene: Are humans now overwhelming the great forces of nature. Ambio, 36 (8), 614-621.

Paula Guerra. Doutora em Sociologia. Professora de Sociologia da Faculdade de Letras e Investigadora do Instituto de Sociologia da Universidade do Porto. Professora Adjunta no Griffith Center for Social and Cultural Studies na Austrália. Investigadora colaboradora no Centro de Investigação Transdisciplinar «Cultura, Espaço e Memória», no Centro de Estudos de Geografia e Ordenamento do Território e no DINÂMIA'CET-IUL - Centre for Socioeconomic Change and Territorial Studies, Portugal. Faculdade de Letras da Universidade do Porto, Via Panorâmica, s/n, 4150-564 Porto, Portugal. E-mail: pguerra@letras.up.pt. ORCID: 0000-0003-2377-8045.

Lígia Dabul. Doutora em Sociologia. Professora Colaboradora dos Programas de Pós-Graduação em Sociologia e em Estudos Contemporâneos das Artes da Universidade Federal Fluminense. Coordenadora do Nectar Núcleo de Estudos Cidadania, Trabalho e Arte da Universidade Federal Fluminense. Poeta. Universidade Federal Fluminense, R. Miguel de Frias, 9 - Icaraí, Niterói - RJ, 24220-900, Brasil. E-mail: ligia.dabul@gmail.com. ORCID: 0000-0002-6224-9720.

\section{Citação:}

Guerra, Paula \& Dabul, Lígia (2020). Dentro das brumas do tempo. Considerações preliminares acerca do antes, do durante e do pós pandemia nas artes e na sociedade. Todas as Artes. Revista Luso-brasileira de Artes e Cultura, 3(3), pp. 4-9. ISSN 2184-3805. DOI: 10.21747/21843805/tav3n3ed 